\title{
THE WIND TURBINE AND THE ENVIRONMENT INTERACTION MODEL
}

\author{
Taras Boyko, Dr. Sc., Prof.; Maria Ruda, PhD, As.-Prof.; Serhiy Stasevych, PhD, \\ Lviv Polytechnic National University, Ukraine; e-mail: tgbo@ukr.net \\ Olha Chaplyk, National Forestry University of Ukraine
}

\begin{abstract}
The modeling of the mutual influence of the wind power plant and the ecosystem is carried out. It is proposed to consider the compartment of a complex landscape complex as an elementary structural element of the ecosystem. The wind power plant is a component of a complex landscape complex and is considered during its life cycle. The categories of environmental impact and the relative contribution of harmful factors for each category have been determined. The modeling was carried out using various scenarios of waste management, which will make it possible to reduce the negative impact of harmful factors for each category. Summary data on the impact of harmful factors on the environment were obtained, and ecological profiles were constructed using the Eco-indicator methodology. Such profiles, together with the weighting factors, allow a comprehensive presentation of environmental impacts and obtaining the values of eco-indicators that characterize the damage caused by a wind turbine to the environment. The process of synthesis of an industrial cyber-physical system is carried out by five typical steps, among which the process of 'cyber-realization' is to create a cyber twin and compare it with the real system. To implement this process, mathematical modeling was carried out, as a result of which a system of differential equations was obtained, the input data for which were the values of environmental impacts, expressed by the specified indicators. The resulting model will act as ideal for a real system 'wind turbine - environment", and will allow predicting the consequences of the harmful impact of a wind turbine on a complex landscape system and will determine the main impacts to achieve its maximum efficiency and adaptation to the requirements for environmental protection and conservation. Some results obtained using the developed model are presented.

Key words: Compartment of complex landscape system, Unconventional energy sources, Life-cycle of industrial product, Cyber-twin, Eco-indicators.
\end{abstract}

\section{Introduction}

The development and deployment of production cyber-physical systems [1] can be implemented in five steps, that is communication, conversion, cyberimplementation, cognition, configuration. "Communication" is to provide feedback using sensors to control the system's behavior. During the "conversion" the collected data is analyzed to identify critical points and potential problems. "Cyber-implementation" aims to create a cyber-twin and compare it with a real device for subsequent synthesis of the system. Throughout "cognition" results of comparison help the user identify potential problems. "Configuration" is to reconfigure the production system to take into account priorities and risks to achieve its maximum efficiency.

The task of creating a "cyber-twin" for a wind turbine that interacts with the environment is a multi-stage process which is proposed to be implemented based on the application of the compartment concept of a complex landscape system (CLS) for an ecosystem [2], as well as the concept of a product life-cycle for wind turbines [3].

The central point of the concept is a compartment that is exposed to environmental pressure from the abiotic nature and anthropogenic factors and is characterized by certain parameters. The CLS is a natural combination of natural components - landscape systems of different taxonomic ranks that interact and form a single system. A compartment is an elementary functional element of the CLS that performs one or several functions, inherent in its properties, behavior, and context of the application.

The concept of the life-cycle of products assumes that each product is characterized by stages of development which together make up its life-cycle, and each of the stages provides a specific impact on the environment. At all stages of the life-cycle of a wind turbine as a product, when energy is produced, certain pollution of the ecosystem occurs.

Optimal management of ecosystem states involves advanced technologies based on intelligent information systems, as well as the processing of experimental data. Sustainable development of any region, as an integral socio-ecological-economic system, requires an adequate apparatus for informing about the state of the environment, appropriate simulation models, and reliable methods for modeling the assessment of the ecosystem.

\section{Data Analysis and Purpose}

\section{of the Studies}

Over the last half-century, many scientists around the world have been dealing with the problems of modeling processes and systems of non-traditional and renewable energy sources of various levels. However, the impact of alternative energy sources on the environment has been studied much less today than the economic or other impacts [4-5]. References' analysis permits to reveal that the problems of wind energy are mainly dealt with in technical terms, studying the issues of further improving the wind turbines design and technologies, or considering the efficiency of wind energy, ways of rational distribution and accumulation of electricity [6]. At the same time, "intelligent" technologies are being developed, namely Smart Grid, Smart Metering, Demand Response, and others to enhance the efficiency and reliability of power supply [7]. However, their impact on the environment has hardly been studied.

The proposed study is based on an integrated approach that simulates the interaction of SLC and energy objects throughout its life-cycle trying to model 
the interaction of considered and environmental systems. The Life-Cycle Assessment (LCA) method, based on a series of ISO standards, can be the base method [8,9] for assessing the potential environmental impacts of wind farms [10-14]. Not many current life-cycle assessment studies exist for wind turbines of high-rated power (600 $\mathrm{kW}$ ). The available studies [15] demonstrate that the ecological indexes of wind turbines highly depend on the production and types of applied materials that can have harmful environmental effects, as well as on indirectly generated waste. Interaction between wind turbines and the CLS is advisable to consider based on the compartment concept of the latter.

Similarly, are regarding SLK as a system that should be characterized by a structure made of natural components of different taxonomic ranks. Considering the wind turbines located within the SLC, it is characterized by the structural and functional unity of biotic and abiotic components. And the biotic component consists of some hierarchically related subsystems and layers, between which exist material-energy and causal relationships. This made it possible to determine the initial conditions and limits of the simulation.

\section{Methods of the Study}

ISO 14040/44 standard defines the concept of LCA as a set of comprehensive environmental characteristics of a product, where a quantitative measurement of their environmental friendliness is the result of the passing processes.

The SimaPro software applied for LCA supports EPDs, GHG protocol, and ILCD Handbook; they provide for five stages of research: 1 - definition of the purpose and subject of research; 2 - the formation of the model of the life cycle of the wind turbine with the display of all the environmental inputs and outputs; 3 assessment of the wind turbine impact on the compartments of the CLS; 4 - obtaining specific values of impacts and interpreting the results; 5 - modeling the impacts of wind turbines on the subsystems and layers of the CLS compartments. The values of the eco-indicators are obtained using the Eco-indicator method.

1. Modeling the impacts of wind turbines on the CLS compartments. Let the CLS consist of $n$ compartments that exchange flows of matter $f_{A B}$ (from $A$ to $B)$. Each compartment or its elementary structural element (block) is associated with the surrounding abiotic environment or other compartments by lateral connections, the external ones of which are input and output flows. As a whole, they also respond to external impacts, first of all to anthropogenic ones. For landscape science, space is, first of all, the territory, filled with these compartments. Thus, to explore space (territory) means to characterize these compartments. Let the CLS compartment be represented in the form of a hierarchically organized system (graph), consisting of the following 6 subsystems: forest stand, young growth, undergrowth, grass-shrub layer, moss layer, soil. In turn, each subsystem consists of hierarchically sequential layers. In particular, for the "forest stand" subsystem, such layers are needles (leaves) $\leftrightarrow$ shoots of the current year $\leftrightarrow$ branches $\leftrightarrow$ internal bark $\leftrightarrow$ external bark $\leftrightarrow$ wood without bark $\leftrightarrow$ roots. For subsystems "young growth" and "undergrowth", the layers are needles (leaves) $\leftrightarrow$ twigs $\leftrightarrow$ stemwood $\leftrightarrow$ bark $\leftrightarrow$ roots. For the subsystem "grass-shrub layer", the layers are aboveground phytomass $\leftrightarrow$ underground phytomass. For the subsystem "moss layer", the layers are the living part $\leftrightarrow$ the dead part. For the subsystem "soil", the layers are forest floor, which is divided into fresh litter $\leftrightarrow$ fungi-saprotrophs $\leftrightarrow$ semidecomposed litter $\leftrightarrow$ fungi saprotrophs $\leftrightarrow$ decomposed litter; mineral layers: main horizons $\leftrightarrow$ additional horizons $\leftrightarrow$ additional, relatively separated morphological elements of the soil. As a result of the interaction of the listed natural components and anthropogenic factors, the specific system of CLS of various taxonomic ranks is formed. Let us dwell on the modeling of the processes of wind turbine influence on the subsystems and layers of the CLS compartments. In the presented system, all values acquire mainly three indices: $i_{1}$ - to denote the area of space (CLS compartment); $i_{2}$ - to denote the geophysical environment, and $i_{3}-$ to indicate the impact. Then the expression $Q_{i_{1} i_{2} i_{3}}$ will mean the influence of wind turbines at all stages of the life cycle $i_{3}$, in the layers or subsystems $-i_{2}$, CLS compartment $-i_{1}$. Such indices are called multi-indices and are denoted by one letter $i=\left(i_{1} i_{2} i_{3}\right)$, and the set of multi-indices in the model - by the letter $\Omega[16,17]$.

If the CLS consists of $n$ compartments and $m$ impacts are considered, then:

$$
1 \leq i_{1} \leq n ; \quad 1 \leq i_{2} \leq f ; \quad 1 \leq i_{3} \leq m .
$$

Let $Q_{i}$ be the impact of $i_{3}$ in the layers or subsystems $i_{2}$ of the compartment growth area $i_{1}$ that arises at time $t$. Denote by $k_{i j}(\tau)$ the value of this impact, which after time $\tau$ will be in the layers or subsystems $j_{2}$ of the growth region $j_{1}$, having carried out in the process of transforming the flow of matter $f$ into the impact of $j_{3}$. Since the impacts in the process of transfer from the layers to the subsystems of the compartment and from the compartment to another compartment do not arise and do not disappear, then:

$$
\sum_{j=\Omega} k_{i, j}=\sum_{j_{1}=1}^{n} \sum_{j_{2}=1}^{f} \sum_{j_{3}=1}^{m} k_{i_{1} i_{2} i_{3} j_{1} j_{2} j_{3}}=1 .
$$

As a result of observing the value of the impact $Q_{i}$ for each multi-index $i$, we obtain an expression that determines the dynamics of the distribution of the observed impacts for different layers and subsystems of the compartment, in particular:

$$
{ }^{t+\tau} Q=\sum_{i=\Omega}{ }^{t} Q_{i} k_{i, j}(\tau), i \in \Omega,
$$

where ${ }^{t} Q_{i}$ is the system state at the point of time $t$. The state ${ }^{t_{r}} Q$ at the point of time $t_{r}$ is related to the state ${ }^{t_{r-1}} Q$ at the point of time $t_{r-1}$ by:

$$
{ }^{t_{r}} Q={ }^{t_{r-1}} Q K,
$$


where $K$ is a linear operator characterizing the process of spreading and transforming influence or pollutant in layers and subsystems during time $\tau$, and is inherent in the next properties: if the operator $K$ is used $n$ times for the initial state ${ }^{0} Q$, then we receive:

$$
{ }^{n} Q={ }^{n-1} Q K,
$$

Such processes can be studied with help of the theory of the Markovian chains, the main result of which is: for any ${ }^{0} Q$ the sequence of events is defined as ${ }^{n} Q=$ ${ }^{n-1} Q \cdot K$ and goes to some ${ }^{*} Q$ so that $\lim ^{n} Q(i)={ }^{*} Q(i)$ for any $i \in \Omega$.
The states of CLS compartments can be represented by a hierarchical structure in the form of graphs with vertices that identify these states, for example, $S_{1}-$ "good"; $S_{2}$ - "satisfactory"; $S_{3}-$ "unsatisfactory"; $S_{4}$ - "bad". The coefficients $k_{i, j}(t)$ are the probabilities of the states $P_{i, j}(t)$ of the corresponding matrix of states $P$ and the appropriate transition intensity $\lambda_{i, j}(t)$ for transition intensities $\Lambda$ of harmful substances concentration or compartments from state $i$ to state $j$.

Formalization of graphs describing the interaction of the CLS compartment and wind turbine is carried out employing the Kolmogorov system of differential equations:

$$
\left\{\begin{array}{l}
\frac{d P_{i, j, S_{1}}}{d t}=-\lambda_{i, j, S_{1}, S_{2}} \cdot P_{i, j, S_{1}}+\lambda_{i, j, S_{1}} \cdot P_{i, j, S_{2}} ; \\
\hdashline \frac{d P_{i, j, S_{l}}}{d t}=\lambda_{i, j, S_{l-1}, S_{l}} \cdot P_{i, j, S_{l-1}}-\left(\lambda_{i, j, S_{l-1}}+\lambda_{i, j, S_{l}, S_{m}}\right) \cdot P_{i, j, S_{1}}+\lambda_{i, j, S_{m}, S_{l}} \cdot P_{i, j, S_{m}} ; \\
\frac{d P_{i, j, S_{m}}}{d t}=\lambda_{i, j, S_{l}, S_{m}} \cdot P_{i, j, S_{l}}-\left(\lambda_{i, j, S_{m}, S_{l}}+\lambda_{i, j, S_{m}, S_{m+1}}\right) \cdot P_{i, j, S_{m}}+\lambda_{i, j, S_{m}, S_{m+1}} \cdot P_{i, j, S_{m+1}} \\
\hdashline \frac{d P_{i, j, S_{n}}}{d t}=\lambda_{i, j, S_{n-1}, S_{n}} \cdot P_{i, j, S_{n-1}}-\lambda_{i, j, S_{n}, S_{n-1}} \cdot P_{i, j, S_{n}} ;
\end{array}\right.
$$

where $i=1,2, \ldots, N$ and $j=1,2, \ldots, M$ are ordinal numbers of multi indexed $i$ and $j$, respectively; $S_{1}, \ldots, S_{l}, S_{m}, \ldots, S_{n}$ are states of CLS compartments; $P_{i, j, S_{l}}$ is the probability of location the CLS compartment or the concentration of harmful substances in the state $S_{l}$ or the state $S_{m}$; $\lambda_{i, j, S_{l}, S_{m}}$ is the intensity of the transitions of the CLS compartments or the concentration of harmful substances from the state $S_{l}$ to the state $\underline{S}_{\underline{m}}$ for each multi-index.

If, for example, we restrict to $m, l=1,2,3,4$ and $m \neq l$, then the system of differential equations will take the form (7), and solving them with the help of computer technology, it is possible to study the development of the CLS in dynamic and stationary modes:

$$
\left\{\begin{array}{l}
\frac{d P_{i, j, S_{1}}}{d t}=-\lambda_{i, j, s_{1}, s_{2}} \cdot P_{i, j, S_{1}}+\lambda_{i, j, s_{2}, s_{2}} \cdot P_{i, j, S_{2}} \\
\frac{d P_{i, j, S_{2}}}{d t}=\lambda_{i, j, s_{1}, s_{2}} \cdot P_{i, j, S_{1}}-\left(\lambda_{i, j, s_{2}, s_{1}}+\lambda_{i, j, s_{2}, s_{3}}\right) \cdot P_{i, j, S_{2}}+\lambda_{i, j, s_{3}, s_{2}} \cdot P_{i, j, S_{3}} \\
\frac{d P_{i, j, S_{3}}}{d t}=\lambda_{i, j, s_{2}, s_{3}} \cdot P_{i, j, S_{2}}-\left(\lambda_{i, j, s_{3}, s_{2}}-\lambda_{i, j, s_{3}, s_{4}}\right) \cdot P_{i, j, S_{3}}+\lambda_{i, j, s_{4}, s_{3}} \cdot P_{i, j, S_{4}} \\
\frac{d P_{i, j, S_{4}}}{d t}=\lambda_{i, j, s_{3}, s_{4}} \cdot P_{i, j, S_{3}}-\lambda_{i, j, s_{4}, s_{3}} \cdot P_{i, j, S_{4}}
\end{array}\right.
$$

The values of the intensities of transitions from state to state for each element of the hierarchical structure (layers and subsystems of the compartment) are statistical information obtained by studying the functioning of the CLS. To assess and predict the states of these CLSs and their compartments, it is advisable to collect information about the impact of wind turbines at the stages of their life cycle at different time intervals of the CLS functioning. At the same time, such information can be obtained through simulation.
2. Simulation computer modeling of the process of obtaining the results of experimental studies on wind turbines during their life cycle. The simulation of the process of experimental studies of wind turbines was carried out with help of SimaPro program which allows obtaining relatively reliable data on environmental impacts expressed in eco-indices based on a set of input information characterizing a technogenic object. In our case, a process was simulated that covers the LC formation of a virtual wind farm in real conditions of the Ukrainian Carpathians. 
The study of the impact of wind farms on the environmental components was performed taking into account several technical characteristics of wind turbines which are the main equipment of the project. A wind farm consists of individual sections, with facilities and equipment being located on them. Given the wind and weather conditions on the territory of the planned activities, as well as noise, vibration, and other characteristics, wind turbines of the Siemens SWT DD142 company have been chosen. Most of the data come from the LCA report made out by the Vestas company and from the Siemens SWT DD-142 Universal Specification.

The stationary wind farm facilities include wind farm operation control system and facilities, repair and maintenance facilities and distribution points with power equipment and utility systems, tower foundations, wind turbine towers, supports, overhead and underground lines, access roads, and other auxiliary structures and utilities necessary for the operation and life of wind farms.

When mounting the wind turbines, the presence of roads for the transportation of equipment and the possibility of accessing them were taken into account as well as the orientation of the turbine conjugated with the dominant wind directions and the distances between the turbines trying to reduce the impact on the environment and the population of nearby settlements, and so on.

In the location area of wind turbines, it is planned to create temporary construction sites for the installation and maintenance of facilities. Another category is land plots which are temporarily used for storing structural parts. Along the rows of wind turbines, underground cable and communication lines and technological roads are designed.

The manufacturing processes impacting the environment are as follows: production of materials and equipment necessary for the manufacture of components of wind turbines and auxiliary structures and foundations (concrete, aluminum, steel, fiberglass, etc.); operation of the existing roads for transportation by specialized trucks of components of wind turbines and other equipment from the place of their manufacture to the place of installation; installation of wind turbines utilizing cranes; the land plot with an area of 1.25 hectares to store the structural parts; visual impact of wind turbines up to 150 $\mathrm{m}$ high (blades dimension); flickering shadow, noise and vibration from the rotation of the blades and the operation of generators; electromagnetic radiation of overhead and cable power lines and transformer substations; impact on the aquatic environment. Since data on energy consumption for each manufacturing process are not available, the total energy consumption was determined for the entire manufacture of wind turbines and amounts to 7,405 MWh/year of electricity.
The following possible waste management scenarios have been considered. In particular for the type of waste such as steel and ferrous metals, $90 \%$ of steel and iron are recycled; $10 \%$ of steel inactive in landfill conditions is stored on the ground; for waste type: copper - $90 \%$ is recycled; the remaining $10 \%$ of copper, inactive in the landfill, is stored on the ground. Energy consumption in the production of copper is 130.3 $\mathrm{GJ} / \mathrm{t}$ and the cost of its recycling is $20 \%$ of the production (13\% when recycling, $20 \%$ when put in dead storage); for the type of waste: concrete - $100 \%$, inactive in landfill conditions, is stored on the ground; plastics $-100 \%$ of plastics and fiberglass are burned. Disposal of polyethylene terephthalate requires $0.2 \%$ of water during combustion in municipal furnaces; during transportation, it is assumed that the place for recycling, soil storage, an incinerator is located on average $200 \mathrm{~km}$ from the place of installation of wind turbines. Then, for every ton of processed material, there is $200 \mathrm{~km}$ of transportation by a truck with a carrying capacity of 28 tons.

Based on the given description, the defined manufacturing processes, stages of the life-cycle of wind turbines and the data entered into the program, an inventory of components and materials was carried out (Table 1).

Based on all the data presented, the SimaPro program generated a process tree to identify potential environmental impacts. All input and output flow during the LC of wind turbines are grouped in such a way that each of the groups represents a selected impact category. Similarly, the inventory table is arranged so that for each category of impact, all relevant emissions or material consumptions are taken into account qualitatively and quantitatively.

Although the choice of impact categories was partly subjective, it was adjusted to adequately represent the impact on the environment caused by wind turbines. In particular, these are widely recognized environmental problems, such as carcinogenic effects - 1, effects of respiratory inorganics -2 and organics -3 , climate change - global warming -4 , radiation effects -5 , ozone layer depletion -6 , ecotoxicity -7 , acidification and eutrophication -9 , land use -10 , depletion of minerals -11 and fossil fuels -12 .

Fig. 1 presents certain assessments, divided into four stages of the life cycle: manufacture, operation, transportation, and disposal. This makes it possible to identify precisely those stages of LC that have a significant impact directly on the environment. For example, manufacturing significantly contributes to resource depletion. 
Inventory table for the manufacture (assembly) of wind turbine

\begin{tabular}{|c|c|c|c|}
\hline Component & Sub-component & Material & Quantity \\
\hline \multirow[t]{4}{*}{ Rotor } & Blades & Glass-reinforced plastics & $53 \mathrm{t}$ \\
\hline & \multirow[t]{3}{*}{ Hub w/nose cone } & Cast iron & $35 \mathrm{t}$ \\
\hline & & Low-alloy steel & $21 \mathrm{t}$ \\
\hline & & Glass-reinforced plastics & $1.4 \mathrm{t}$ \\
\hline \multirow[t]{11}{*}{ Nacelle } & \multirow[t]{2}{*}{ Generator } & Copper & $10 \mathrm{t}$ \\
\hline & & Electrical steel & $23 \mathrm{t}$ \\
\hline & \multirow[t]{2}{*}{ Gearbox } & Cast iron & $42 \mathrm{t}$ \\
\hline & & High-alloy steel & $42 \mathrm{t}$ \\
\hline & Housing & Glass-reinforced plastics & $10 \mathrm{t}$ \\
\hline & \multirow[t]{2}{*}{ Mainframe } & Cast iron & $35 \mathrm{t}$ \\
\hline & & Low-alloy steel & $19 \mathrm{t}$ \\
\hline & \multirow[t]{2}{*}{ Main shaft } & High-alloy steel & $27 \mathrm{t}$ \\
\hline & & Low-alloy steel & $4.8 \mathrm{t}$ \\
\hline & \multirow[t]{2}{*}{ Transformer } & Copper & $7.8 \mathrm{t}$ \\
\hline & & Electrical steel & $18 \mathrm{t}$ \\
\hline \multirow[t]{3}{*}{ Tower } & Tubular steel & Low-alloy steel & $350 \mathrm{t}$ \\
\hline & \multirow[t]{2}{*}{ Tower internals } & Aluminum & $2.6 \mathrm{t}$ \\
\hline & & Copper & $1.3 \mathrm{t}$ \\
\hline \multirow[t]{3}{*}{ Foundation } & Ballast & Gravel & $5,200 \mathrm{t}$ \\
\hline & Concrete & Concrete & $1,300 \mathrm{~m}^{3}$ \\
\hline & Reinforcement & Reinforcement steel & $560 \mathrm{t}$ \\
\hline
\end{tabular}

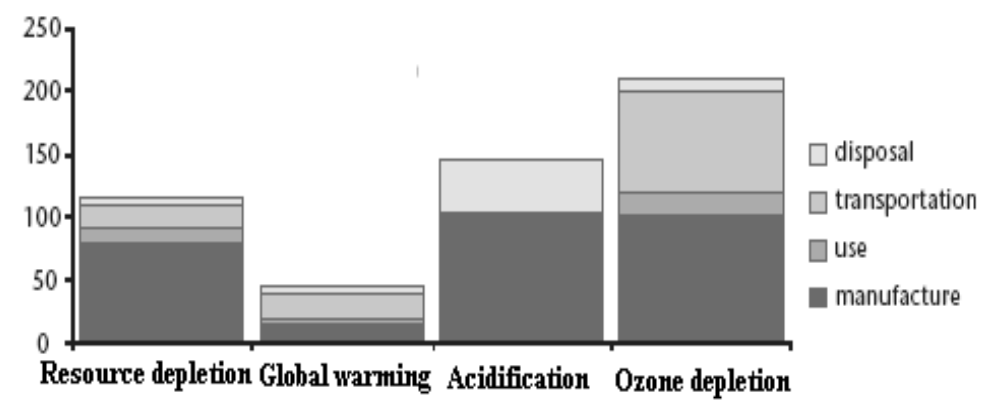

Fig. 1. Environmental profile considering the stages of the life-cycle of wind turbines

The results obtained cannot be compared, since they are presented in different units. To compare them, the normalization procedure is performed, which makes it possible, by comparing the categories of impact, to determine which consequences have the highest priority. The effect normalized assessment is the percentage of annual contribution of a certain product to this effect in a certain area.

The next step is weighing the categories by multiplying the values of the normalized environmental profile by the weighting factor assigned to the category. Weighing is usually based on subjective considerations. To compare the impacts, weighting factors are determined by: the decision of a group of experts - the methods of Eco-indicator 99 and ReCiPe; Ecological Scarcity methods; monetary assessment of damage EPS 2000 method.
During the next step, the load exposure is calculated with help of European average data. The Ecoindicator approach identifies three categories of damage: human health, ecosystem quality, and resource depletion. The first category includes carcinogens, respiratory substances, climate change, radiation, ozone layer depletion, and ecotoxicity. Ecosystem quality includes acidification/eutrophication and land handling. The third category includes natural resources, minerals, and fossil fuels.

Eco-indicator values for a given impact are expressed as the sum of the impacts for each of the three categories. Each of the categories of impact is expressed by one unit. The effect on human health is estimated as DALY - Disability Adjusted Life Years. The impact on the ecosystem quality is given as PAF $\times \mathrm{m}^{2} \times$ year and $\mathrm{PDF} \times \mathrm{m}^{2} \times$ year $(\mathrm{PAF}-$ Potentially Affected Fraction and PDF - Potentially Disappeared Fraction). Resource 
depletion is accessed as the surplus of energy required for the subsequent extraction of minerals and fossil fuels.

Table 2 shows the weighting factors obtained in the study for the three used categories of damage: human health, ecosystem quality, and resources.
Fig. 2 demonstrates the distribution of the values of environmental indicators obtained in the study for four stages of the wind farm life cycle: manufacture; dismantling and disposal; operation; transportation and installation.

Table 2

Eco-indicator weighting factors

\begin{tabular}{|c|c|c|c|c|}
\hline Substance & Damage category & $\begin{array}{l}\text { Hierarchies } \\
\text { weights }\end{array}$ & $\begin{array}{l}\text { Egalitarian } \\
\text { weights }\end{array}$ & $\begin{array}{l}\text { Individualist } \\
\text { weights }\end{array}$ \\
\hline \multicolumn{5}{|c|}{ Resource use (/kg) } \\
\hline Coal (29.3 MJ/kg) & Resources & 0.00599 & 0.0687 & 0 \\
\hline Crude oil (41 MJ/kg) & Resources & 0.140 & 0.114 & 0 \\
\hline Natural gas $(30.3 \mathrm{MJ} / \mathrm{kg})$ & Resources & 0.108 & 0.0909 & 0 \\
\hline Aluminium ore & Resources & 0.0119 & 0.0168 & 0.667 \\
\hline Copper ore & Resources & 0.00987 & 0.0140 & 0.553 \\
\hline Iron ore & Resources & 0.000690 & 0.000976 & 0.0387 \\
\hline Zinc ore & Resources & 0.00178 & 0.00253 & 0.10 \\
\hline \multicolumn{5}{|c|}{ Ecosystem quality land use $(/ \mathrm{m} 2$ year or $/ \mathrm{m} 2)$} \\
\hline Industrial area & Occupation $(/ \mathrm{m} 2$ year $)$ & 0.0655 & 0.0819 & 0.0466 \\
\hline Industrial area & Conversion $(/ \mathrm{m} 2)$ & 1.96 & 2.45 & 1.39 \\
\hline Forest land & Occupation (/m2 year) & 0.00858 & 0.0107 & 0.00610 \\
\hline Forest land & Occupation (/m2 year) & 0.0897 & 0.112 & 0.0637 \\
\hline Forest land & Conversion $(/ \mathrm{m} 2)$ & 2.68 & 3.35 & 1.91 \\
\hline \multicolumn{5}{|c|}{ Emission to air $(/ \mathrm{kg})$} \\
\hline $\mathrm{CO}$ & Human health, respiratory & 0 & 0.00579 & 0 \\
\hline $\mathrm{CO} 2$ & Human health, climate & 0.0297 & 0.0222 & 0.0497 \\
\hline NH3 & Human health, respiratory & 0.0902 & 0.673 & 0.938 \\
\hline NH3 & Ecosystem quality & 1.21 & 1.52 & 0.863 \\
\hline NH3 & Sum, NH3 to air & 2.112 & 2.193 & 1.801 \\
\hline
\end{tabular}

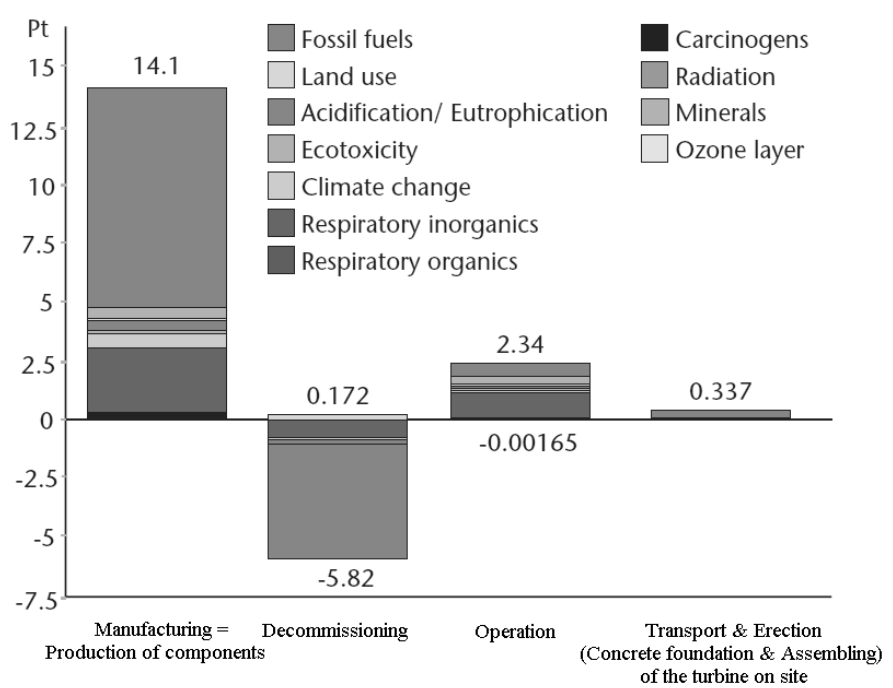

Fig. 2. Ecological indicators of the life cycle of wind farms for four stages

3. Predicting the consequences of the harmful influence of wind turbines on the CLS. Prediction of the effects of harmful substances and the states of the CLS compartment, as a hierarchical structure in dynamic and stationary modes, can be realized by solving a system of differential (7) and algebraic equations (13) utilizing information technologies and the presented data obtained applying the computer models of studies on wind turbines during their life cycle in the SimaPro program and the Eco-indicator method. In this case, the states of the compartments included in the system of equations (7) can be expressed using the Eco-indicator methodology through the influence presented in ecopoints (Fig. 2). Let the hierarchical structure of the states 
of the compartment be identified as $S_{1}$ - "normal"; $S_{2}-$ "below normal"; $S_{3}$ - "above normal"; $S_{4}$ - "significantly above normal",

The study of the dynamics of states of hierarchical structures and their elements is proposed to be carried out based on solving systems of differential equations (7) using the fourth-order numerical Runge-Kutta method, the record of which in general term takes the form (8):

$$
\begin{aligned}
& y_{k+1}=y_{k}+\frac{1}{6}\left(K_{1}+2 K_{2}+2 K_{3}+K_{4}\right) \\
& K_{1}=f\left(x_{k}, y_{k}\right) \Delta x \\
& K_{2}=f\left(x_{k}+\frac{\Delta x}{2}, y_{k}+\frac{K_{1}}{2}\right) \Delta x \\
& K_{3}=f\left(x_{k}+\frac{\Delta x}{2}, y_{k}+\frac{K_{2}}{2}\right) \Delta x \\
& K_{4}=f\left(x_{k}+\Delta x, y_{k}+K_{3}\right) \Delta x
\end{aligned}
$$

To solve the system of differential equations (7), using the indicated numerical method in a dynamic mode, we reduce them to the form:

$$
\begin{aligned}
& \frac{d P_{0}}{d t}=a_{00} \cdot P_{0}(t)+a_{01} \cdot P_{1}(t)+a_{02} \cdot P_{2}(t)+\ldots+a_{0 n} \cdot P_{n}(t), \\
& \frac{d P_{1}}{d t}=a_{10} \cdot P_{0}(t)+a_{11} \cdot P_{1}(t)+a_{12} \cdot P_{2}(t)+\ldots+a_{1 n} \cdot P_{n}(t), \\
& \frac{d P_{2}}{d t}=a_{20} \cdot P_{0}(t)+a_{21} \cdot P_{1}(t)+a_{22} \cdot P_{2}(t)+\ldots+a_{2 n} \cdot P_{n}(t),
\end{aligned}
$$

$$
\begin{aligned}
& \frac{d P_{m}}{d t}=a_{m 0} \cdot P_{0}(t)+a_{m 1} \cdot P_{1}(t)+a_{m 2} \cdot P_{2}(t)+\ldots+a_{m n} \cdot P_{n}(t), \\
& P_{0}(t)+P_{1}(t)+P_{2}(t)+\ldots+P_{n}(t)=1 .
\end{aligned}
$$

Under the given initial conditions:

$$
P(0)=\left(\begin{array}{c}
P_{0}(0) \\
P_{1}(0) \\
P_{2}(0) \\
\cdots \cdots \\
P_{n}(0)
\end{array}\right)=\left(\begin{array}{l}
P_{00} \\
P_{10} \\
P_{20} \\
\cdots \\
P_{n 0}
\end{array}\right),
$$

using the methods of approximate calculations and computer technology, the solution of the system of equations (7) can be written as:

$$
P_{i, k+1}=P_{i k}+\frac{H}{6} \cdot\left(K_{1 i}+2 \cdot K_{2 i}+2 \cdot K_{3 i}+K_{4 i}\right),
$$

where

$$
\begin{aligned}
& K_{1 i}=\sum_{j=0}^{n} a_{i j} \cdot P_{j k}, i=0,1,2, \ldots, n ; \\
& K_{2 i}=\sum_{j=0}^{n} a_{i j} \cdot\left(P_{j k}+K_{1 i} \cdot \frac{H}{2}\right), i=0,1,2, \ldots, n ; \\
& K_{3 i}=\sum_{j=0}^{n} a_{i j} \cdot\left(P_{j k}+K_{2 i} \cdot \frac{H}{2}\right), i=0,1,2, \ldots, n ; \\
& K_{4 i}=\sum_{j=0}^{n} a_{i j} \cdot\left(P_{j k}+K_{3 i} \cdot H\right), i=0,1,2, \ldots, n ; \\
& H=\Delta t .
\end{aligned}
$$

The study of the CLS as an object with a hierarchical structure in the stationary mode, when $t \rightarrow \infty$ and $\frac{d P}{d t}=0$, is carried out with help of numerical methods based on the solution of algebraic equations system:

$$
\begin{aligned}
& -\lambda_{i, j, s_{1}, s_{2}} \cdot P_{i, j, S_{1}}+\lambda_{i, j, s_{2}, s_{2}} \cdot P_{i, j, S_{2}}=0 \\
& \lambda_{i, j, s_{1}, s_{2}} \cdot P_{i, j, S_{1}}-\left(\lambda_{i, j, s_{2}, s_{1}}+\lambda_{i, j, s_{2}, s_{3}}\right) \cdot P_{i, j, S_{2}}+\lambda_{i, j, s_{3}, s_{2}} \cdot P_{i, j, S_{3}}=0, \\
& \lambda_{i, j, s_{2}, s_{3}} \cdot P_{i, j, S_{2}}-\left(\lambda_{i, j, s_{3}, s_{2}}-\lambda_{i, j, s_{3}, s_{4}}\right) \cdot P_{i, j, S_{3}}+\lambda_{i, j, s_{4}, s_{3}} \cdot P_{i, j, S_{4}}=0 \\
& \lambda_{i, j, s_{3}, s_{4}} \cdot P_{i, j, S_{3}}-\lambda_{i, j, s_{4}, s_{3}} \cdot P_{i, j, S_{4}}=0
\end{aligned}
$$

whose matrix notation takes the form:

$$
\Lambda \cdot P=0,
$$

where $\Lambda$ is the matrix of intensities of transitions from state to state; $P$ is the matrix of state probabilities.

To obtain the solution to the investigated system of equations (7) in a stationary mode, we reduce them to:

$$
\begin{aligned}
& a_{00} \cdot P_{0}+a_{01} \cdot P_{1}+a_{02} \cdot P_{2}+\ldots+a_{0 n} \cdot P_{n}=0 \text {, } \\
& a_{10} \cdot P_{0}+a_{11} \cdot P_{1}+a_{12} \cdot P_{2}+\ldots+a_{1 n} \cdot P_{n}=0 \text {, } \\
& a_{20} \cdot P_{0}+a_{21} \cdot P_{1}+a_{22} \cdot P_{2}+\ldots+a_{2 n} \cdot P_{n}=0 \text {, }
\end{aligned}
$$

Using the Khaletsky scheme of the Gauss numerical method [22], we find $P_{n}, P_{n-1}, \ldots, P_{0}$ in the following order:

$$
\begin{aligned}
& P_{0}+a_{01} \cdot P_{1}+a_{02} \cdot P_{2}+\ldots+a_{0 n} \cdot P_{n}=0, \\
& P_{1}+a_{12} \cdot P_{2}+\ldots+a_{1 n} \cdot P_{n}=0 \text {, } \\
& P_{n}=0
\end{aligned}
$$

with recurrent formulas:

$$
\begin{aligned}
& \gamma_{i 0}=a_{i 0},(i=0,1,2, \ldots, n), \\
& \alpha_{0 k}=\frac{\alpha_{0 k}}{\alpha_{00}},(k=1,2, \ldots, n), \\
& \gamma_{i k}=a_{i k}-\sum_{j=0}^{k-1} \gamma_{i j} \cdot \alpha_{j k},(i, k=1,2, \ldots, n ; n \geq k), \\
& \alpha_{i k}=\frac{1}{\gamma_{i i}} \cdot\left(a_{i k}-\sum_{j=k}^{i=1} \gamma_{i j} \cdot \alpha_{j k}\right),(i, k=1,2, \ldots, n ; i<k) .
\end{aligned}
$$

The presented algorithms for obtaining input data, construction, and solution of systems of differential and algebraic equations can be applied as a basis for studying the states of the CLS compartment and estimating the impacts of wind turbines on the environment. Table 3 presents the results of the probable simulating impact of wind turbines during the four stages of the life-cycle (see Fig. 1) on the subsystems and layers of the CLS compartments. The last is confirmed the research "Study of the presence of plants and animals listed in the Red Book of Ukraine and plant groups that are protected by the legislation of Ukraine in the territory of the planned activity". 
The impact of wind turbine life-cycle on the subsystems and compartments of the CLS

\begin{tabular}{|c|c|c|c|c|c|}
\hline $\begin{array}{l}\text { Stage of WT life } \\
\text { cycle }\end{array}$ & $\begin{array}{l}\text { Area \& } \\
\text { Substance }\end{array}$ & Compartment & Unit & Total & $\begin{array}{l}\text { Formalized description of } \\
\text { subsystems and layers of the } \\
\text { compartment affected by the impact } \\
\text { of wind turbine LC }\end{array}$ \\
\hline 1 & 2 & 3 & 4 & 5 & 6 \\
\hline \multirow[t]{14}{*}{ Transport } & $\begin{array}{l}\text { The occupied } \\
\text { area is the } \\
\text { industrial area }\end{array}$ & \multirow[t]{3}{*}{$\begin{array}{l}\text { Grass-shrub layer \& soil } \\
\text { subsystem of the forest } \\
\text { compartment }\end{array}$} & ha & 0.2 & Soil compaction \\
\hline & Cetane & & $\%$ & 47 & \multirow{5}{*}{ Pollution } \\
\hline & $\begin{array}{c}\text { Alfamel- } \\
\text { naphthalene }\end{array}$ & & $\%$ & 53 & \\
\hline & $\mathrm{CO}$ & \multirow{3}{*}{ Air } & $\mathrm{kg}$ & 18 & \\
\hline & $\mathrm{CO}_{2}$ & & $\mathrm{~kg}$ & 17.5 & \\
\hline & $\mathrm{C}_{\mathrm{x}} \mathrm{H}_{\mathrm{y}}$ & & $\mathrm{kg}$ & 14.3 & \\
\hline & The occupied & \multirow[b]{2}{*}{ Fauna } & $\mathrm{dBa}$ & 80.0 & Changing migration routes \\
\hline & $\begin{array}{l}\text { area as the } \\
\text { industrial area }\end{array}$ & & $X$ & $\mathrm{X}$ & $\begin{array}{l}\text { Vehicles crash. } \\
\text { The intrusion of invasive species. }\end{array}$ \\
\hline & Acid as $\mathrm{H}^{+}$ & \multirow{6}{*}{ Wastewater } & $\mathrm{g}$ & 21 & \multirow{6}{*}{ Pollution } \\
\hline & BOD & & $\mathrm{g}$ & 412 & \\
\hline & Calcium ions & & $\mathrm{g}$ & 25 & \\
\hline & $\mathrm{Cl}$ & & $\mathrm{mg}$ & 17 & \\
\hline & COD & & $\mathrm{g}$ & 14 & \\
\hline & $\mathrm{C}_{\mathrm{x}} \mathrm{H}_{\mathrm{y}}$ & & $\mathrm{g}$ & 36 & \\
\hline \multirow{9}{*}{$\begin{array}{l}\text { Transport \& Erection } \\
\text { (Concrete foundation } \\
\text { \& Assembling) of the } \\
\text { turbine on site }\end{array}$} & & $\begin{array}{l}\text { Grass-shrub layer of the } \\
\text { compartment }\end{array}$ & ha & $\sim 30.6$ & $\begin{array}{l}\text { Extinction or damage to especially } \\
\text { valuable species }\end{array}$ \\
\hline & $\begin{array}{l}\text { The occupied } \\
\text { area as the } \\
\text { industrial area }\end{array}$ & $\begin{array}{c}\text { aboveground phytomass of } \\
\text { the Grass-shrub layer of the } \\
\text { compartment }\end{array}$ & $\mathrm{X}$ & $\mathrm{X}$ & $\begin{array}{l}\text { Destruction of or damage to a } \\
\text { variety of herbaceous communities } \\
\text { - Hypochoeridi uniflorae-Nardetum } \\
\text { i Hieracio vulgati-Nardetum, } \\
\text { according to the classification of } \\
\text { biotopes Eur } 28 \text { (EUNIS 6230) - } \\
\text { species-rich Nardus grasslands and } \\
\text { fragments of relict phytocoenoses } \\
\text { with the dominance of arcto-alpine } \\
\text { species Juncus trifidus L., which can } \\
\text { be considered within the association } \\
\text { Oreochloetum (distichae) juncosum } \\
\text { (trifidi), listed in the Green Book of } \\
\text { Ukraine }\end{array}$ \\
\hline & \multirow{4}{*}{$\begin{array}{l}\text { The occupied } \\
\text { area as the } \\
\text { industrial area }\end{array}$} & (land use) & $\mathrm{X}$ & $\mathrm{X}$ & $\begin{array}{l}12 \text { types of settlements that are } \\
\text { subject to protection (namely: } \\
\text { 'C2.12', 'C2.18', 'C2.19', 'C2.25', } \\
\text { 'D2.226', 'D2.3', 'E1.71', 'E4.11', } \\
\text { 'E4.3', 'E5.5', 'F4.2', 'G1.6'). }\end{array}$ \\
\hline & & $\begin{array}{l}\text { soil subsystem of the forest } \\
\text { compartment }\end{array}$ & ha & $\sim 30.6$ & $\begin{array}{l}\text { Removal of the top fertile layer of } \\
\text { soil. Wind and water erosion. } \\
\text { Changes in the soil profile. }\end{array}$ \\
\hline & & (land use) & $\mathrm{X}$ & $\mathrm{X}$ & Change of hydrological regime \\
\hline & & Fauna & $X$ & $\mathrm{X}$ & $\begin{array}{l}\text { Strengthening the edge effect. } \\
\text { Loss of natural habitats, nesting } \\
\text { sites, food for birds and bats. }\end{array}$ \\
\hline & $\mathrm{CO}$ & \multirow{3}{*}{ Air } & $\mathrm{kg}$ & 27 & \multirow{3}{*}{ Pollution } \\
\hline & $\mathrm{CO}_{2}$ & & $\mathrm{~kg}$ & 17 & \\
\hline & $\mathrm{C}_{\mathrm{x}} \mathrm{H}_{\mathrm{y}}$ & & $\mathrm{kg}$ & 14 & \\
\hline \multirow[t]{2}{*}{$\begin{array}{l}\text { Operation } \\
\text { Maintenance }\end{array}$} & \multirow{2}{*}{$\begin{array}{l}\text { The occupied } \\
\text { area as the } \\
\text { industrial area }\end{array}$} & $\begin{array}{l}\text { soil subsystem of the forest } \\
\text { compartment }\end{array}$ & ha & $\sim 30.6$ & Soil compaction \\
\hline & & Fauna & $X$ & $\mathrm{X}$ & $\begin{array}{c}\text { Damage to bats and birds during a } \\
\text { collision with wind turbines, power } \\
\text { lines }\end{array}$ \\
\hline
\end{tabular}


Continuation of Table

\begin{tabular}{|c|c|c|c|c|c|}
\hline 1 & 2 & 3 & 4 & 5 & 6 \\
\hline & & (land use) & $\mathrm{m}$ & 150 & $\begin{array}{l}\text { Influence on the visual perception of } \\
\text { the environment }\end{array}$ \\
\hline & $\begin{array}{l}\text { Fuel and } \\
\text { lubricants }\end{array}$ & $\begin{array}{l}\text { Grass-shrub layer of the } \\
\text { compartment }\end{array}$ & ha & 0.003 & Possible spills when replacing parts \\
\hline & BOD & Wastewater & $\mathrm{g}$ & 456 & Surface run-off \\
\hline \multirow[t]{12}{*}{ Decommissioning } & $\begin{array}{l}\text { The occupied } \\
\text { area as the } \\
\text { industrial area }\end{array}$ & $\begin{array}{l}\text { grass-shrub layer \& soil } \\
\text { subsystem of the forest } \\
\text { compartment }\end{array}$ & ha & $\sim 30,6$ & $\begin{array}{l}\text { Extinction of or damage to } \\
\text { especially valuable species }\end{array}$ \\
\hline & Acid as $\mathrm{H}^{+}$ & \multirow{7}{*}{ Wastewater } & $\mathrm{g}$ & 48 & \multirow{7}{*}{ Pollution } \\
\hline & BOD & & g & 850 & \\
\hline & Calcium ions & & $\mathrm{g}$ & 47 & \\
\hline & $\mathrm{Cl}$ & & $\mathrm{mg}$ & 37 & \\
\hline & COD & & $\mathrm{g}$ & 76 & \\
\hline & $\mathrm{C}_{\mathrm{x}} \mathrm{H}_{\mathrm{y}}$ & & $\mathrm{g}$ & 26 & \\
\hline & Detergent/oil & & $\mathrm{mg}$ & 49 & \\
\hline & $\begin{array}{l}\text { The occupied } \\
\text { area as the } \\
\text { industrial area }\end{array}$ & Fauna & $\mathrm{X}$ & $\mathrm{X}$ & $\begin{array}{l}\text { Hindering the free migration of } \\
\text { animal species }\end{array}$ \\
\hline & $\mathrm{CO}$ & \multirow{3}{*}{ Air } & $\mathrm{kg}$ & 23 & \multirow{3}{*}{ Pollution } \\
\hline & $\mathrm{CO}_{2}$ & & $\mathrm{~kg}$ & 20 & \\
\hline & $\mathrm{C}_{\mathrm{x}} \mathrm{H}_{\mathrm{y}}$ & & $\mathrm{kg}$ & 19 & \\
\hline
\end{tabular}

\section{Conclusions}

1. The interaction of the complex landscape system compartment and wind turbine during life-cycle, have been simulated with help of SimaPro program and the Eco-indicator'99 methodology. Information on the quantitative indicators of the spread of pollutants and harmful factors in the layers and subsystems of the mentioned system was obtained.

2. Estimation of the ecological profiles and weighting factors facilitated the presentation of the impact factors during the life cycle of the wind turbine in the form of eco-indicators, distributed over four stages: manufacture; operation; transportation, and installation; dismantling and disposal. The greatest harmful environmental impact with an eco-indicator value of 14.1 occurs during the manufacturing stage of wind turbines.

3. The developed model regards the real wind turbine-environment system and becomes able to predict the consequences of the harmful effects of wind turbines on the environment.

\section{Conflict of interest}

The authors state that there are no financial or other conflicts regarding the work.

\section{References}

[1] Cyber-physical Systems. Metrological Issues, Coeditors S. Yatsyshyn, B. Stadnyk. IFSA Publishing, Barcelona, 2016. [Online]. Available: https://opac.lpnu.ua/bib/1081014.

[2] M. Lenzen, J. Munksgaard, "Energy and CO2 lifecycle analyses of wind turbines", Rev. \& Appl., Renewable Energy, Vol. 26, Iss. 3, pp. 339-362, Jul. 2002 [Online]. Available: DOI: 10.1016/S0960-1481(01)00145-8.
[3] M. Lenzen, U. Wachsmann, "Wind turbines in Brazil and Germany: an example of geographical variability in life-cycle assessment", Appl. Energy, Vol. 77, pp. 119-130, 2004 [Online]. Available: https://isa.org.usyd.edu.au/education /documents/ISA_Wind_turbine_LCA_2004.pdf

[4] T. Burton, N. Jenkins, D. Sharpe, E. Bossanyi, Wind energy handbook, 201, books.google.com, [Online]. Available: https://scholar.google.com.ua/scholar?q=Burton+T., + Sharpe $+\mathrm{D}$ ., +Jenkins + N., + Bossanyi + E. $+(2001),+$ Wind + energy\&hl=uk\&a s_sdt $=0 \&$ as_vis $=1 \&$ oi $=$ scholart

[5] IHS Markit's Top 10 Cleantech Trends in 2021 [Online]. Available: https://ihsmarkit.com/Info/0121/clean energytechtrends2021.html

[6] L. Schleisner, "Life cycle assessment of a wind farm and related externalities", Renewable Energy, Int. Journ. of Life Cycle Assessment, Vol. 20, Iss. 3, pp. 279-288, July 2000. DOI: 10.1016/S0960-1481(99)00123-8[Online]. Available: https://econpapers.repec.org/article/eeerenene/v_3a20_3ay_3a2 000 3ai 3a3 3ap 3a279-288.htm

[7] N. Jungbluth, C. Bauer, R. Dones, R. Frischknecht, "Live Cycle Assessment for Emerging Technologies: Case Studies for Photovoltaic and Wind Power", Int. Journ. of Life Cycle Assessment, Vol. 10; Iss. 1, 2005 [Online]. Available: https://ur.booksc.eu/book/11432656/1f5ccd

[8] ISO 14040 : 2006, Environmental management Life cycle assessment - Principles and framework, 2006 [Online]. Available: https://www.iso.org/standard/37456.html

[9] ISO/TR 14047:2003. Environmental management Life cycle impact assessment - Examples of application of ISO 14042, [Online]. Available: https://www.iso.org/standard/ 31026.html

[10] B. Cleary, A. Duffy, A. O'Connor, "Using life cycle assessment to compare wind energy infrastructure", in Proc. of Int. Symp. on Life Cycle Assessment and Construction. Conf. Papers, pp. 31-39, 2012. [Online]. Available: https://arrow.tudublin.ie/engschcivcon/31/ 
[11] Martinez, F. Sanz, S. Pellegrini, "Life cycle assessment of a multi-megawatt wind turbine", Renewable Energy, Vol. 34, Iss. 3, pp. 667-673, 2009.

[12] C. Chenai, "Life cycle analysis of wind turbine", Sustainable Development - Energy, Engineering and Technologies - Manufacturing and Environment. 2012. [Online]. Available: https://cdn.intechopen.com/pdfs/29930/ InTech-Life_cycle_analysis_of_wind turbine.pdf

[13] T. Toth, S. Szegedi, "Anthropogeomorphologic impacts of onshore and offshore wind farms, Acta climatologica et chorologica, Iss. 40-41, pp. 147-154, 2007.

[14] P. Razdan, P. Garrett, "Life Cycle Assessment of Electricity Production from a Onshore V110 - 2.0 MW Wind
Plant", 2015 [Online]. Available: https://www.vestas.com/content/ dam/vestas-com/global/en/sustainability/reports-andratings/lcas/LCAV11020MW181215.pdf.coredownload.inline.pdf

[15] Danish Energy Authority, Annual and monthly statistics. [Online]. - Available: https://ens.dk/en/our-services/ statistics-data-key-figures-and-energy-maps/annual-andmonthly-statistics

[16] Wind Europe [Online]. - Available: http://www. ewea.org/index.php?id $=196$

[17] B. P. Weidema, E. Lindeije, "Physical impacts of land use in product life cycle assessment", Final report of the EURENVIRON-LCAGAPS sub-project on land use, 2001 [Online]. Available: https://lca-net.com/files/gaps9.pdf 